\title{
AVANÇOS E DESAFIOS DA EDUÇAÇÃO AMBIENTAL BRASILEIRA ENTRE A RIO92 E A RIO+20
}

Patricia Bastos Godoy Otero ${ }^{1}$

Zysman Neiman ${ }^{2}$

Resumo: O artigo discute os avanços e os desafios do campo da Educação Ambiental (EA) brasileira, no período entre as duas grandes Conferências sobre Meio Ambiente e Desenvolvimento promovidas pela Organização das Nações Unidas (ONU) e realizadas no Brasil, a Rio-92 e a Rio+20, que aconteceram respectivamente em 1992 e 2012. O principal objetivo foi analisar a evolução da Educação Ambiental brasileira no período entre as duas grandes Conferências, elaborada a partir da sistematização de informações de documentos oficiais, reportagens publicadas pela mídia sobre os dois eventos e entrevistas com lideranças ambientalistas, políticos e técnicos que estiveram nos eventos e que atuam com, destaque no campo da Educação Ambiental do Brasil.

Palavras-chave: Educação Ambiental; Sustentabilidade; Desenvolvimento Sustentável. 


\section{Introdução}

O Tratado de Educação Ambiental para Sociedades Sustentáveis e Responsabilidade Global (TEASS), emanado da Conferência das Nações Unidas sobre Meio Ambiente e Desenvolvimento (Rio de Janeiro, 1992) considera que a EA para uma sustentabilidade equitativa "é um processo de aprendizagem permanente, baseado no respeito a todas as formas de vida. Tal educação afirma valores e ações que contribuem para a transformação humana e social e para a preservação ecológica”.

Segundo Nieves-Alvarez (2002), é necessário que a escola assuma um comportamento adequado, pois educar em uma perspectiva ambiental significa assumir novos conceitos e novos conhecimentos, aplicar procedimentos diversos e criar atitudes, valores e normas que levem a comportamentos que favoreçam o meio.

A Educação Ambiental (EA) é eminentemente interdisciplinar, participativa, comunitária, criativa, crítica da realidade vivenciada, formadora da cidadania.e valoriza a ação, ou seja, é orientada para a resolução de problemas locais (GUIMARÃES, 1995). É transformadora de valores e atitudes por meio da construção de novos hábitos e conhecimentos, criadora de uma nova ética, sensibilizadora e conscientizadora para as relações integradas ser humano/sociedade/natureza objetivando o equilíbrio local e global, como forma de obtenção da melhoria da qualidade de todos os níveis de vida.

A educação, como instrumento de preservação ou de transformação da sociedade, é objeto de discussão antiga e está novamente no centro das sugestões de redefinições ou reorganizações do pensamento da humanidade. A visão holística de EA é orientada pelo processo, ao contrário de ser orientada pelo produto - revisando e reavaliando a educação e o aprendizado como intrínsecos à vida (ROSA, 2001).

Segundo Ramalho (2004), na visão holística, o sujeito, ao conhecer-se a si mesmo - objetivo fundamental da educação - desperta para a cidadania consciente por meio de práticas baseadas na verdade e no descomprometimento com valores sociais que perpetuam a destruição cada vez maior do meio ambiente.

Para Mininni-Medina (2001), o conceito de EA incorpora a complexidade das inter-relações sistêmicas da problemática ambiental, a análise de suas potencialidades socioculturais e ambientais e a necessidade de construção de novas modalidades de relação dos homens entre si e com a natureza, formuladas a partir do paradigma da sustentabilidade. A prática da EA, para a autora, tem como um dos seus pressupostos, o respeito aos processos sociais, culturais, étnicos, característicos de cada país, região ou comunidade.

A integração dos diversos enfoques científicos e comunitários, num processo interdisciplinar, se dá por meio da construção de um modelo mental baseado na ideia de interação entre os diferentes fatores que incidem num problema. É um processo cíclico, em que duas ou mais espécies de conceitos 
evoluem conjuntamente e conduzem à compreensão de um novo nível de complexidade (BOVO, 2007). A transversalidade e a interdisciplinaridade são, nesse sentido, modos de trabalhar o conhecimento que visam reintegração de dimensões isoladas uns dos outros pelo tratamento disciplinar.

A EA traz consigo uma nova pedagogia, segundo Leff (2001), que surge da necessidade de orientar a educação dentro do contexto social e na realidade ecológica e cultural onde se situam os sujeitos e atores do processo educativo.

Foi na Conferência de Tbilisi (Ex-URRS) em 1977 que o termo meio ambiente foi definitivamente ampliado, passando a incluir as dimensões antrópicas, éticas, estéticas, históricas etc. Esta compreensão foi reiterada pelo TEASS. Em 2012, na Conferência da ONU denominada Rio+20, esse documento foi novamente debatido e revalidado. O objetivo deste artigo é discutir os avanços e desafios da EA ante o amadurecimento do debate sobre seus pressupostos e modos de ação, e o processo de estabelecimento de políticas públicas no Brasil entre 1992 e 2012, intervalo entre as duas grandes conferencias internacionais ocorridas no país.

\section{As grandes conferências Rio92 e Rio+20 e a Educação Ambiental no período Rio92 e o Fórum Global das Organizações Não Governamentais}

Conforme colocado por Moura (2000), a Conferência do Rio de Janeiro sobre Meio Ambiente e Desenvolvimento realizada em 1992 foi um inquestionável indutor para a abordagem ambiental no mundo. Na Rio92 ou Cúpula da Terra, como ficou conhecida, teve a participação de 172 países, mais de mil e quatrocentas ONG's e dez mil participantes. Foi realizada entre 3 e 14 de junho de 1992, no Rio de Janeiro (RJ) e reuniu 108 chefes de Estado que buscavam meios de conciliar o desenvolvimento socioeconômico com a conservação e proteção dos ecossistemas da Terra.

A Rio92 inseriu o Brasil no debate ambiental global, abriu espaço para que entidades da sociedade civil participassem mais das negociações entre os governos preparando um terreno fértil para o florescimento das organizações não governamentais ambientalistas. Lá foram elaborados a Agenda 21 e a Carta da Terra, que tiveram impacto direto no desenvolvimento e consolidação da EA brasileira como estratégia transversal para as mudanças propostas, dando origem a ações coordenadas em rede, globalmente e no Brasil: a Rede Brasileira de Agendas $21^{3}$ e a Rede Brasileira da Carta da Terra, esta última lançada na Rio+20.

O Fórum Global das Organizações Não Governamentais contou com a participação de 15.000 profissionais da área ambiental. Nesse evento foram ratificados 32 tratados, dentre eles TEASS, que teve e tem especial influência na EA brasileira.

${ }^{3}$ REBAL - http://rebal21.ning.com/ e Rede Bras. da Carta da Terra http://www.cartadaterrabrasil.org/.

Revbea, São Paulo, V. 10, Nº 1: 20-41, 2015. 
Um dos impactos da Rio92 e do Fórum Global foi a disseminação inicial da ideia de organização em rede, padrão que vem sendo favorecido pela conectividade intensiva proporcionada pelo desenvolvimento das tecnologias de Internet. No Brasil, houve a criação da Rede Brasileira de Educação Ambiental - REBEA, criada na atmosfera de grande mobilização que antecedia a Rio92 e que adotou como padrão organizacional a estrutura horizontal em rede. Nos últimos anos, esta rede experimentou um processo de expansão e fortalecimento de suas articulações no país inteiro, tendo se transformado numa "rede de redes" com mais de 50 outras redes de educadores ambientais. A REBEA completou 20 anos em junho de 2012.

\section{Rio+20 e a Cúpula dos Povos}

A Conferência das Nações Unidas sobre Desenvolvimento Sustentável foi realizada entre 13 e 22 de junho de 2012, na cidade do Rio de Janeiro. A Rio+20 foi assim conhecida porque marcou os vinte anos de realização da Conferência das Nações Unidas sobre Meio Ambiente e Desenvolvimento (Rio92). Seu objetivo foi a renovação do compromisso político com o desenvolvimento sustentável, por meio da avaliação do progresso e das lacunas na implementação das decisões da Rio92 e o tratamento de temas novos e emergentes.

A Conferência teve dois temas principais: a economia verde no contexto do desenvolvimento sustentável e da erradicação da pobreza; e a estrutura institucional para o desenvolvimento sustentável. A Comissão Nacional para a Conferência das Nações Unidas sobre Desenvolvimento Sustentável teve a atribuição de articular os eixos da participação do Brasil na Conferência. A sociedade civil foi parte integral da Comissão Nacional, contando com cerca de quarenta membros, representantes de diversos setores sociais, selecionados em processo transparente e inclusivo.

Cerca de 110 mil pessoas foram ao Rio de Janeiro para os eventos oficiais. Aproximadamente 45 mil pessoas estiveram presentes no Riocentro, local que sediou a conferência da ONU, e mais de 1 milhão de participantes estiveram nos eventos paralelos, com destaque para a Cúpula dos Povos, no Parque do Flamengo, e para o Espaço Humanidade2012, no Forte de Copacabana.

De acordo com a prefeitura do Rio de Janeiro, foram registradas 23 manifestações, sendo que o protesto que reuniu maior número de pessoas foi o realizado no dia 20 de Junho de 2012, quando 50 mil ativistas, indígenas, professores e estudantes ocuparam as avenidas Presidente Vargas e Rio Branco. A Rio+20 rendeu cerca de 700 compromissos voluntários entre ONGs, empresas, governos e universidades. Isso significa um investimento de US\$ 513 Bilhões para ações de desenvolvimento sustentável nos próximos 10 anos. 
200 universidades de 50 países se comprometeram a tornar a Sustentabilidade o eixo norteador dos projetos pedagógicos e PDIs ${ }^{4}$.

O principal documento elaborado foi a declaração $O$ Futuro que Queremos, assinado por 188 países. As avaliações sobre o evento reconhecem perdas e ganhos resumidamente analisadas nos próximos parágrafos.

Ban Ki-moon Secretário-Geral $\mathrm{ONU}^{5}$, no encerramento da Rio+20, considera que o documento final demonstra convergência na criação de Objetivos de Desenvolvimento Sustentável. O Secretário enfatizou a adesão voluntária às proposições, pois todos assumiram quase 700 compromissos, representando centenas de bilhões de dólares.

Segundo relata Leitão (2012), eventos ocuparam toda a cidade do Rio de Janeiro, como nunca antes no campo ambiental: 220 mil pessoas e suas famílias passaram mais de 3 horas nas filas diárias para a exposição Humanidades2012, no Forte de Copacabana; quinhentos cientistas de vários países passaram dias trocando informações na PUC; pessoas decidiram mudar de atitude; empresários compararam práticas, e prefeitos se comprometeram a mudar a realidade local. Para a jornalista,

isso não mudará o mundo, nem deterá a mudança climática, mas tornará cada vez mais penoso para os governos adiar a inadiável adoção de políticas públicas e decisões políticas que reduzam o risco que corremos. A ação individual tem impacto! O intangível legado da Rio+20 é este. Seus milhares de eventos paralelos podem ter tocado pessoas. Quem sabe quantas crianças verão o mundo com outros olhos? E isso pode ser decisivo (s/p).

Para Viana (2012) a Rio+20 promoveu uma enorme penetração da temática da sustentabilidade para além do território de ambientalistas, ecólogos e alguns poucos líderes visionários de outros setores. Para o jornalista, era difícil imaginar, por exemplo, que presidentes de grandes bancos, como o Bradesco e BNDES, gastariam cada vez mais tempo com temas relacionados à sustentabilidade, ou que a CNI reuniria em um evento paralelo mais de 1.100 líderes empresariais para apresentar propostas concretas para uma produção industrial realmente sustentável.

A Presidente Dilma Rousseff, no entanto, de acordo com a mídia nacional, reconheceu a morosidade dos processos decisórios num mundo que precisa de rapidez nas decisões para enfrentar os desafios ambientais, sociais e econômicos e destacou o multilateralismo como uma das principais

\footnotetext{
${ }^{4}$ Fonte: Editorial do Jornal O Estado de São Paulo, 24/06/2012.

${ }^{5}$ Site da ONU: http://www.onu.org.br/rio20/rio20-termina-e-documento-final-o-futuro-que-queremos-eaprovado-com-elogios-e-reservas/
}

Revbea, São Paulo, V. 10, Nº 1: 20-41, 2015. 
conquistas da Rio+20. No jargão diplomático, a presidente afirmou que a Rio+20 é uma conferência de partida, ou seja, que lança processos para que alguns assuntos - como os Objetivos do Desenvolvimento Sustentável - sejam tratados e definidos nos próximos anos.

Já Gro Brundtland, que coordenou o relatório Nosso Futuro Comum, avaliando os produtos das duas conferências, Rio92 e Rio+20, declarou: "uma comparação entre esse novo documento e a 'Agenda 21' aprovada em 1992 é inevitável, com grande vantagem para os 40 capítulos da velha agenda" (MARCONDES, 2012: 1).

$\mathrm{Na}$ mesma matéria, Marcondes (op. cit:1) cita o diretor executivo do Fundo de Populações das Nações Unidas, o nigeriano Babatunde Osotimehin, para quem o crescimento das demandas de consumo, principalmente nos países emergentes, reforça uma enorme pressão sobre os recursos naturais:

Planejar para as mudanças previstas no tamanho da população e tendências como o envelhecimento, migração e urbanização é uma condição indispensável para estratégias sustentáveis de desenvolvimento (MARCONDES, 2012, p.1).

Houve também participação de muitas empresas, o que para alguns evidenciou que a Rio+20 foi uma oportunidade para o capitalismo apresentar uma versão mais sustentável. A ex-ministra Marina Silva disse que "a conferência foi capturada por interesses corporativos" (MARCONDES, 2012, p.1).

Iniciativa importante apresentada foi a criação, pela Universidade da ONU e parceiros, de um Índice de Riqueza Inclusiva (IWR), que acrescentará aos atuais métodos de avaliação do desenvolvimento - crescimento do Produto Interno Bruto (PIB) e Índices de Desenvolvimento Humano do PNUD, indicadores para avaliar a situação dos recursos naturais, sua preservação ou perda (NOVAES, 2012).

A Cúpula dos Povos foi o evento paralelo à Rio+20, organizado por entidades da sociedade civil e movimentos sociais de vários países. Aconteceu entre os dias 15 e 23 de junho no Aterro do Flamengo, com o objetivo de discutir as causas da crise socioambiental, apresentar soluções práticas e fortalecer movimentos sociais do Brasil e do mundo. Recebeu quase 23 mil inscritos, dos quais foram selecionados 15 mil representantes da sociedade civil, vindos de várias partes do mundo, em especial das Américas, Europa e norte da África, além dos cerca de 300 mil visitantes. O grupo responsável pela organização foi o Comitê Facilitador da Sociedade Civil Brasileira para a Rio+20 (CFSC).

Durante a Rio+20 e a Cúpula dos Povos aconteceram quatro eventos relacionados à II Jornada e à Educação Ambiental, entre eles o lançamento da Rede Planetária do Tratado de Educação Ambiental, durante a mesa redonda 
Educação para sociedades sustentáveis na Agenda Rio+20 e Você: O Tratado de Educação Ambiental e as Metas do Desenvolvimento Sustentável como Diretrizes nas Iniciativas de Responsabilidade Social Ambiental.

Outro ponto de destaque foi o acordo em que as instituições de ensino superior do Brasil e do mundo se comprometem a incluir o tema sustentabilidade assumindo o compromisso com práticas sustentáveis nas Instituições de Ensino Superior.

Como contraponto ao resultado oficial da Rio+20 foi lançada a União Global pela Sustentabilidade ${ }^{6}$ movimento internacional aberto que promove a união de forças entre pessoas, organizações não governamentais, empresas e governos locais, a partir de objetivos e compromissos voluntários de ações de mudança, em prol do desenvolvimento sustentável.

\section{Educação Ambiental Brasileira da Rio92 à Rio +20}

\section{Entrevistas com especialistas na temática ambiental}

Para a realização desta etapa da pesquisa, entramos em contato com líderes ambientalistas que militam na EA e que estiveram presentes em ambos os eventos (Rio92 e Rio+20), de modo a resgatar o contexto histórico que vivem e viveram os depoentes, e cruzar informações e lembranças das duas Conferências, para se configurar o cenário dos desafios da EA de acordo com essas lideranças. Cada um foi entrevistado individualmente, entre 23 de junho de 2012 e 13 de maio de 2013, tendo seus depoimentos gravados e transcritos (alguns enviaram suas respostas já por escrito).

São os seguintes os entrevistados e as datas nas quais deram seus depoimentos:

- Aron Belinky (12 de março 2013): Articulador da Rio+20, pesquisador e consultor, tem formação em Administração Pública pela FGV-SP e Geografia pela USP;

- Doroty Martos (23 de junho 2012): Mestre em Educação pela UMESP e Gestora Ambiental pela FMU/SP.

- Fábio Feldmann (24 de outubro de 2012): Advogado (USP) e administrador de empresas (FGV) foi eleito Deputado Federal por três mandatos consecutivos (1986 - 1998), chefe da delegação brasileira dos parlamentares na Rio92;

- Monica Pilz Borba (21 de abril 2013): Pedagoga pela PUC/SP e especialista em EA pela FESP/USP. Criou e coordena o Instituto 5 Elementos;

- Nilo Sérgio de Melo Diniz (13 de maio 2013): È Comunicador Social (UNB) e fundador FBOMS. Ë Diretor do Departamento de Educação

\footnotetext{
${ }^{6}$ Site da União Global pela Sustentabilidade: http://www.globalunionforsustainability.org/
} 
Ambiental da Secretaria de Articulação Institucional e Cidadania Ambiental do Ministério do Meio Ambiente;

- Pedro Jacobi (21 de abril de 2013): Cientista social e economista, é Professor Associado da Faculdade de Educação (USP). Mestre em planejamento Urbano pela Graduate School of Design Harvard University e doutor em sociologia (USP).

- Thais Corral (03 de dezembro de 2012): Fundadora e Coordenadora da Rede de Desenvolvimento Humano (REDEH). Fez Administração (FGV), especialização pela Universidade de Camerino, (Itália), mestrado pelas Universidades de Chicago (EUA), Los Andes (Colômbia), e Harvard.

O roteiro de entrevistas era comum a todos, e constava basicamente das seguintes questões: 1) Em sua opinião, o cenário sociopolítico em 1992 possibilitou a emergência de práticas sociais que contribuíram para gerar processos de Educação Ambiental? 2) Quais foram os eventuais avanços do campo da EA no período entre a Rio92 e a Rio+20? Houve a almejada construção de outra relação da humanidade com o meio ambiente, ou seja, a transformação de pessoas em prol de uma sociedade sustentável? 3) Quais são os desafios e as dificuldades que você apontaria para a EA nesse período? 4) Passado esse período você se considera otimista ou pessimista com os avanços/retrocessos da questão ambiental e da EA? Porque?

Para tentar elaborar um quadro reflexivo que possa responder a essas perguntas, procuramos ouvir a opinião de especialistas, que foram entrevistados através de uma abordagem semiestrutural, de modo a responder como cada um entendia os avanços e/ou retrocessos da EA nesse período. Depois de colhidos os depoimentos, esses foram sistematizados, registrando a opinião e a memória social em estilo mais narrativo, de acordo com Bosi (2003). As opiniões dos entrevistados foram então confrontadas com os principais fatos relativos às políticas públicas de EA nesse período, de modo a compor o painel que se segue.

\section{Cenários: Eco92 e Rio+20}

Uma evidência que surge após os depoimentos dos entrevistados é que em 1992 havia uma clara consciência da crise, que fez acontecer a própria Rio92 numa tentativa de países membros da ONU de negociarem uma agenda para lidar com os problemas ambientais,

Em 1992 havia um ambiente muito otimista, o momento que estávamos vivendo, era quase de euforia, começo da globalização, com internet chegando, Constituição Brasileira de 1988 recém-aprovada, redemocratização do Brasil, queda do muro de Berlim. Pegada muito positiva no mundo, impulso positivo, pensando nos espaço da cidadania (Aron Belinky). 
A elaboração do texto da Política Nacional de Educação Ambiental (PNEA) começou em 1992, por iniciativa do Deputado Federal Fábio Feldmann, sendo aprovada apenas em 1999 (Lei n`9.795, regulamentada pelo Decreto $n^{\circ}$ 4281/02) (BRASIL, 1999), e proporcionou a abertura de um espaço institucional para tratar a EA como uma política de governo (MENDONÇA, 2004).

A Rio92 abriu espaço para que entidades da sociedade civil participassem e dialogassem nas negociações entre os governos. Fábio Feldman, autor do texto da PNEA, considera que a mobilização da sociedade civil no Fórum Global, foi uma das grandes contribuições da Rio92, pois se

[...] demonstrou a vitalidade das organizações não governamentais, de personalidades e líderes de todo o mundo que criaram um evento paralelo, muitas vezes confundido com a própria reunião dos governos, a Rio92, realizada no Riocentro [...]. A partir do Fórum Global, a sociedade civil ganhou uma legitimidade incontestável, passando-se a reconhecer que as sociedades nacionais não têm, nos seus governos, seus representantes únicos e exclusivos [...] (Fábio Feldmann).

Nilo Diniz comenta sobre o Fórum Brasileiro de ONGs e Movimentos Sociais para Meio Ambiente e Desenvolvimento (FBOMS), afirmando que 0 mesmo foi

\begin{abstract}
uma articulação intersetorial inédita no país, preparatória da sociedade civil para a Conferência da ONU. Do lado do Governo Federal, sob a orientação do Secretário Nacional de Meio Ambiente (SEMA), o ambientalista José Lutzemberger, formouse uma equipe para elaborar o documento governamental preparatório, que tinha a frente um brasileiro, Roberto Guimarães, administrador público e cientista político, capaz de reunir contribuições que tratavam das questões ambientais articuladas com aspectos sociais e econômicos. Essa abordagem socioambiental associada à dimensão econômica, portanto, presente no olhar das entidades da sociedade civil e do Governo Federal, à época, foi decisiva para consolidar uma mudança importante nos conteúdos e tendências da EA praticada até então. A vertente conservacionista que, de certa forma, prevalecia até final dos anos 1980, passou a ter que dialogar com outra vertente socioambiental, que agregava novos conteúdos, mas também novos atores.
\end{abstract}

Para Nilo, os trabalhos da comissão Brundtland lançados no relatório intitulado "Nosso Futuro Comum" (CMMAD), aproximou as dimensões do desenvolvimento sustentável para a EA, como levantado abaixo 
Um aspecto a se observar sobre a importância deste relatório Brundtland para o tema da EA foi a associação mais evidente entre as dimensões sociais, econômicos e ambientais, no contexto de uma crise global. Isso foi muito pertinente, ao menos no Brasil, porque, ao lado da alta relevância que uma conferência da ONU representava, por si só, para governo e sociedade, incentivou uma ampla articulação entre os diferentes movimentos sociais no Brasil, ambientalistas ou não, que haviam passado por um processo de retomada na década anterior, com a democratização e a Assembleia Nacional Constituinte (Nilo Diniz).

Aron Belinky, aponta que, quanto ao evento oficial (Rio+20), a sociedade civil e os representantes das nações participantes, não estavam convictos das possibilidades do evento.

A Rio+20, ela estava quase que num caminho inverso, por que o ambiente no qual foi construída, nos 2 anos que a antecederam, foram anos em que a mobilização nas Nações Unidas, frente ao sistema multilateral, estava baixa. [...] Aquilo que estávamos aguardando e acreditávamos, ou seja, que na Rio92 fez diferença ter acordos internacionais [...], já não parecia ser tão importante, pois percebemos logo que havia uma baixa capacidade de implantação dos acordos que pudessem surgir. [...] $\mathrm{O}$ que eu acho é que nós, nesses 20 anos, acabamos, do ponto de vista dos impactos, tocando e até ultrapassando os limites seja do planeta de um lado, seja os limites do sistema Estado-Nação como instituição por outro lado, pois o mesmo não é mais suficiente, não dá conta...(Aron Belinky).

Em 2012 a organização da sociedade civil, melhorou sua capacidade de intervenção, controle social e qualificação para atuar em temas complexos. Paralelamente, há maior profissionalização dos militantes e profissionais que trabalham com a questão ambiental, apontando soluções para os que consideram que o tema seja um empecilho para o desenvolvimento.

Quanto a Conferência da ONU, Thais Corral entende que

o evento oficial, foi restrito e tímido, nos resultados. O governo brasileiro criou os diálogos. Os que participaram gostaram. Mas quem garante que os pactos serão implementados? Há necessidade de consolidação da emergência de novos atores [...] reconhecer melhor onde estão as melhores competências. 
O período analisado testemunhou a criação de políticas públicas e marcos regulatórios para a gestão da EA brasileira como a normatização institucional da área ambiental, a criação de políticas setoriais para gerenciamento das águas, resíduos sólidos, e mudanças climáticas, por exemplo. No entanto, ainda há um significativo desafio quanto à estruturação adequada dos órgãos responsáveis para a implantação das políticas propostas. Assim, temos uma situação em que este cenário reflete por um lado avanços, subtraídos de atrasos e recuos.

Aliar os projetos de EA às políticas públicas ainda é um grande desafio, pois os governos têm tantos déficits que nossas ações parecem estar num segundo plano. A Política Nacional de Resíduos Sólidos (PNRS) tem metas ousadas de extinguir os lixões das cidades até 2014 e isso poderá ajudar muito a implantar políticas educacionais eficientes para ampliar a participação do cidadão (Monica Pilz Borba).

Os projetos, nas suas múltiplas dimensões e possibilidades, devem, na medida do possível, abrir-se para o diálogo e sensibilização das pessoas face aos temas que intervém no seu cotidiano, como é o caso dos resíduos sólidos, da poluição do ar e da perda de biodiversidade (Pedro Jacobi).

\section{Avanços do campo da Educação Ambiental}

Através das análises recolhidas encontramos evidências de que há uma ação persistente tanto na institucionalização da EA como no engajamento de pessoas no campo de atuação durante o período analisado.

Em 1997, após dois anos de debates, os Parâmetros Curriculares Nacionais (PCN) foram aprovados pelo Conselho Nacional de Educação, elaborados por professores, especialistas em Educação, contratados pela Secretaria da Educação Fundamental do Ministério da Educação (MEC) (SOUZA, apud BRASIL, 1997: s/p). O objetivo do Tema Transversal Meio Ambiente, para Fontanela (2001), é compreender o ambiente como uma grande teia, da qual o ser humano representa um elemento, e tem como pressuposto que o ser humano faz parte do Meio Ambiente. Os "Parâmetros em Ação: Meio Ambiente na Escola" (PAMA), segundo Mendonça (2004), foi o primeiro programa de formação do MEC a trabalhar com um tema transversal.

Também em 1997, durante a 1 a Conferência de Educação Ambiental, realizada em Brasília, foi produzido o documento Carta de Brasília para a Educação Ambiental. No mesmo ano, aconteceu em Guarapari (ES), o primeiro dos Fóruns Brasileiros de Educação Ambiental, realizado pela REBEA. 
Como avanço mais marcante vejo a realização dos Fóruns de Educação Ambiental, promovidos pela REBEA e que ocorreram em São Paulo, Espírito Santo, Goiás, Rio de Janeiro e Bahia, sendo que em breve haverá um no Norte do país, além dos diversos encontros estaduais (Monica Pilz Borba).

Nessa mesma perspectiva, Nilo Diniz acredita que o Fórum de EA é importante devido a sua capilaridade e importância que tem em todo o país:

Logo depois da Rio92, os Fóruns Brasileiros de EA da REBEA, foram construindo um diálogo nacional dando oportunidade para Redes de EA se firmarem pelo país trazendo diferentes realidades sólidas nas ações de EA (Nilo Diniz).

Em 2001 realizou-se uma parceria entre redes de EA e o MMA, tendo e vista a implantação e alimentação do Sistema Brasileiro de Informação em Educação Ambiental - SIBEA ${ }^{7}$. O Fundo Nacional do Meio Ambiente financiou cinco projetos de redes de educadores e um diagnóstico nacional da $E A$, com o intuito de alimentar o banco de dados do SIBEA. Em junho de 2002, a Lei $n^{\circ}$ 9.795/99, da Política Nacional de Educação Ambiental, foi regulamentada pelo Decreto $n^{\circ} 4.281$.

No ensino universitário surge a Rede Universitária de Programas de Educação Ambiental (RUPEA), criada em 1997. A Associação Nacional de Pós-graduação e Pesquisa em Educação (ANPEd) cria grupos de trabalho temáticos sobre EA em 2002.

$O$ interesse que despertou na comunidade acadêmica se refletiu em pesquisas, dissertações e teses produzidas. [...] Também há de se considerar a importância que assumem os debates e a emergência de diferentes abordagens teóricas que se contrapõem, na medida em que assim como se constroem argumentos pautados pelo conceito de Desenvolvimento Sustentável e suas possibilidades, emergem críticas a estas abordagens, porque não propõem questionamentos estruturais em relação ao modelo existente. Muitos encontros têm sido realizados em nível nacional e internacional e nestes espaços se criam oportunidades para a multiplicação de ideias e de posicionamentos, assim como de ações concretas nos campi e a possibilidade da temática ser inserida nas atividades curriculares. [...] Como avanço, o que considero mais importante, é percepção das possibilidades de pesquisa e ensino numa perspectiva interdisciplinar. (Pedro Jacobi).

\footnotetext{
${ }^{7}$ Site do SIBEA: https://sites.google.com/site/aabrasilma/Home/planos-de-acao/cidadania/educacao-
} ambiental/sistemabrasileirodeinformacaoemeducacaoambiental-sibea 
Desde 1994 funciona o mestrado do Programa de Pós-graduação em Educação Ambiental, na Universidade Federal do Rio Grande (FURG) e em 2005 foi criado o doutorado.

Como expressão desta atividade incessante no campo da EA ocorre a realização constante de seminários, congresso, fóruns, conferências temáticas nos âmbitos municipal, estadual e nacional. Sites, blogs, perfis dedicados aos temas ambientais nas mídias sociais, campanhas digitais, grupos eletrônicos, revistas eletrônicas são formas atuais da comunicação de educadores ambientais que aproveitam das facilidades da web para disseminar, interagir e educar para a sustentabilidade.

Um aspecto muito importante desse período foi a capilaridade da EA. Houve expansão sim, muita gente hoje, independente de formação específica na área, procura se informar e buscar subsídios para trabalhar a educação, pois toda educação tem que ser ambiental (Doroty Martos).

Nos 20 anos estudados ocorreu também uma expressiva expansão da EA no ensino fundamental brasileiro. Recentemente (2012) houve a aprovação da proposta das Diretrizes Curriculares Nacionais para a Educação Ambiental ${ }^{8}$, pelo Conselho Nacional de Educação. Pedro Jacobi reconhece ainda como avanço do campo da EA

[...] a multiplicação de professores que percebem a importância de articular suas atividades docentes com o tema da EA, educação ou aprendizagem social para a sustentabilidade. $O$ mais importante é que a temática não se restrinja a alguns especialistas, mas que se amplie de forma horizontalizada (Pedro Jacobi).

Em relação às políticas de meio ambiente começa a ocorrer a realização de projetos e programas voltados aos municípios e suas articulações regionais, como os consórcios e comitês de bacia hidrográfica.

Avanços também podem ser identificados na área da responsabilidade socioambiental das empresas (não se trata especificamente de EA, mas tem ligações diretas com essa temática), como a adoção dos relatórios anuais sobre sustentabilidade, os estudos de impacto ambiental e a própria evolução tecnológica.

${ }^{8}$ Diretrizes Curriculares Nacionais para a Educação Ambiental:

http://www.icmbio.gov.br/intranet/download/arquivos/cdoc/biblioteca/resenha/2012/junho/Res2012-0618DOUICMBio.pdf

Revbea, São Paulo, V. 10, N 1: 20-41, 2015. 
Nas empresas e suas ações com visibilidade pública, se distinguem aquelas que podem ser denominadas de greenwashing e aquelas que apresentam ações mensuráveis e que indicam compromisso institucional (Pedro Jacobi).

Ainda como política pública, através de uma Instrução Normativa do Ibama, foi estabelecido que a EA é componente do processo de licenciamento ambiental, com atividades educativas para que os diferentes grupos sociais afetados por empreendimentos participem e percebam as consequências de riscos e danos socioambientais decorrente de empreendimentos. Nilo Diniz reconhece como avanço

a EA nestes processos de gestão ambiental em especial no licenciamento ambiental (Nilo Diniz).

\section{Dificuldades e desafios da EA}

Sorrentino et al. (2005) citam alguns programas desenvolvidos em conjunto pelas agências e comissões dos Ministérios do Meio Ambiente e da Educação como é o caso dos "Municípios educadores sustentáveis e a formação de educadores ambientais". No entanto, apesar do visível avanço nas políticas públicas, pelo menos no que concerne à legislação e aos documentos de referência produzidos, cabem as perguntas: essas leis, documentos e fóruns criados são efetivos e atuantes?; Quais as concepções de EA estão por trás de cada um?; O que muda no Brasil?; Os brasileiros se apropriaram disso?; Qual é exatamente o avanço qualitativo entre as duas conferências?

A EA nasceu como crítica a ausência da abordagem dos problemas ambientais pela sociedade, e esta dificuldade é apontada por Pedro Jacobi:

Ainda se observa pouca percepção na sociedade sobre as mudanças que se colocam como essenciais para aproximar-se de uma sociedade que dá importância à sustentabilidade. As iniciativas que se multiplicam, sejam nas escolas, nas universidades, nas empresas, nas ONGs, representam pontos de convergência para a aproximação e diálogo de múltiplos atores face um mesmo objetivo: promover mudanças nos hábitos, nas práticas sociais através de estratégias sensibilizadoras e mobilizadoras. [...] O discurso da economia verde e da importância de perceber os riscos potenciais que coloca a mudança climática compõem atualmente uma agenda para modificar a visão de mundo das pessoas e integrá-las em novas políticas e ações sustentáveis (Pedro Jacobi). 
Nilo Diniz considera que

a crise é parceira da EA, pois mobiliza estratégias (Nilo Diniz).

Para Aron Belinky,

a EA está desafiada a fazer frente a 2 ceticismos: um em relação ao Estado, às políticas públicas à capacidade de intervenção; e outro quanto ao que é um projeto, uma proposta ambientalista de convivência dentro dos limites do mundo. Isso porque, de certa maneira, as pessoas jovens urbanas percebem com muita clareza que a vida moderna tem vantagens (autonomia, liberdade, tecnologia). Elas têm condições de se expressar de se mover e tomar decisões infinitamente maiores, e elas são conscientes disso. Mas esses mesmos jovens, por valorizar esta autonomia, são refratários às cosias que vão em direção oposta, de contenção, 'cuidado não avance', 'reduza'... Esse discurso vai contra a liberdade e autonomia (Aron Belinky).

Ainda segundo o raciocínio de Aron Belinky, há a necessidade de uma transição para outra forma de abordagem.

A EA tem que ser capaz de chegar e se colocar, não como uma coisa de limitação, uma imposição moral, mas como um caminho para o bem estar. No discurso, a questão não é 'salvar o planeta', mas sim 'viver melhor'... O 'vamos salvar o planeta1 está ultrapassado. Em 1992 soava muito bem, mas hoje é uma besteira enorme. Primeiro porque não temos esta capacidade, nem de destruir, nem de salvar. [...] O que são 2000, 5 ou 10 anos de humanidade? [...] A questão é salvar a nós mesmos, é viver melhor... tem a ver com o sentido de você estar menos sujeito à crises, inundações, epidemias, trânsito na cidade, violência, seca, falta da água... Tem um monte de coisas que as pessoas não gostam ou tem medo...

Estamos vendo coisas diferentes, como internet, mídias de massa de mobilização e ainda não as sabemos usar. Estamos começando a aprender a usá-las. É nisso que vejo um caminho de esperança, de onde podem surgir coisas novas. Os cidadãos estão se percebendo, começando a interagir com pessoas do mundo inteiro. 'Antes de ser um brasileiro, italiano ou americano, eu sou um jovem que me interesso por direitos humanos, ou EA, sustentabilidade, natureza'. (Aron Belinky). 
A coordenação da Política Nacional de Educação Ambiental está a cargo do Órgão Gestor (OG), dirigido pelos Ministérios do Meio Ambiente e da Educação, tendo como referencial o documento ProNEA. Neste contexto

um grande desafio para o campo da EA é manter dia a dia o diálogo entre as Secretarias de Educação e de Meio Ambiente. (Nilo Diniz).

Apesar dos avanços quanto ao financiamento e realização de projetos em EA, Monica Pilz Borba, chama a atenção quanto ao tempo de duração desses projetos:

Para promover mudança de comportamento em uma comunidade o projeto tem que acontecer a médio prazo (2 a 4 anos) aliado a políticas públicas locais, promovendo diferentes práticas de sustentabilidade com linguagem adequada a públicos diversificados (Monica Pilz Borba).

\section{Otimista ou pessimista com os avanços/retrocessos da questão ambiental e da EA?}

A EA nos impõe muitos desafios: o da complexidade e o das relações entre os fatores econômicos, ecológicos, socioculturais, geográficos e políticos. E o tempo todo, o campo de atuação dos educadores expõe estas contradições das sociedades, mas com um grande potencial para promover as mudanças socioambientais, com significativo horizonte de possibilidades, como demonstra este testemunho.

Acredito que as EA's (critica, socioambiental, conservadora), são complementares e cada vez mais integradas, articuladas nos diálogos. Momento bom, interessante... Estou otimista com a EA pois há mais segmentos comprometidos, movimentos sociais do campo, meios de comunicação, escolas, parceiros não formais por exemplo (Nilo Diniz),

Monica Pilz Borba é otimista com os avanços da EA e sua trajetória profissional é associada a este sentimento como neste comentário

Estou otimista, senão não poderia continuar a atuar nesta área, apesar de verificar que nossos resultados são muito pouco frente ao desafio que temos. De qualquer forma percebo que a maioria dos problemas que a sociedade de consumo enfrenta tem como raiz a falta de consciência socioambiental, a ausência de um pensamento sistêmico de como tudo acontece aqui neste planeta (Monica Pilz Borba).

Revbea, São Paulo, V. 10, N 1: 20-41, 2015.

revista brasileira

educação

ambiental 
Pedro Jacobi considera que

Os avanços nas práticas educativas são importantes, mas nem sempre na velocidade desejada seja no universo escolar, nas universidades e nas empresas. [...] Nas escolas depende principalmente de liderança na direção e de professores engajados, e se pode observar que na sua maioria dependem de ações pautadas pelo voluntarismo. Nas universidades não é muito diferente, e também depende de líderes e projetos multiplicadores (Pedro Jacobi).

Apesar de encontrarmos tantas iniciativas importantes, muitas delas estruturantes do ponto de vista da implementação da EA como política pública, quando analisamos os depoimentos, deparamos com avaliações críticas e, por vezes, alguma frustração.

Pedro Jacobi, por exemplo, fala sobre a lentidão como um entrave:

$\mathrm{Na}$ gestão pública os resultados são diversos. Muitas prefeituras tem promovido ações inovadoras que estimulam coresponsabilização, outras focadas em ações concretas que promovem transformações no modus operandi. Mas no geral se observa que as mudanças são lentas, erráticas e quase sempre vinculadas a agendas políticas, e que na sua maioria depende de gestores inovadores que visam associar sua ação a uma política de cidades sustentáveis (Pedro Jacobi).

Já com relação ao âmbito federal,

A Política de Educação Ambiental e a Gestão de Resíduos Sólidos é um tema estratégico do Departamento de Educação Ambiental, num diálogo entre a EA e a Comunicação Social, as diretrizes da Política Nacional de Resíduos Sólidos, novas mídias, e participação social tem-se tratado de forma articulada e participativa esse tema (Nilo Diniz).

Quanto à educação formal, observa-se que uma das fragilidades que emergem nas reflexões sobre a implantação da EA é a falta de formação adequada dos professores para que ela deixe de ser uma iniciativa paralela ao currículo e que a escola consiga formar gerações preparadas para viver a sustentabilidade. Para Fábio Feldmann, 
no caso da EA, a minha crítica continua a mesma de vinte anos atrás: teríamos que de fato trabalhar na formação dos professores, com a educação formal, para você criar de um currículo inovador que permitisse trabalhar com a EA como deveria ser. Nesse sentido existe ainda um desafio que é preparar esses professores para que eles, enfim, possam trabalhar a EA no sentido de formar gerações (Fábio Feldmann).

Vemos ainda na constituição deste campo concepções que hipervalorizam a capacidade da EA em promover mudanças complexas na humanidade.

Deveríamos implantar um sistema educacional com base na alfabetização ecológica, pois nosso impacto é tão pesado na atualidade, que somente uma mudança profunda no sistema educacional poderia ajudar a solucionar a continuidade pacífica dos seres humanos na Terra (Monica Pilz Borba).

Pode-se dizer que a institucionalização da EA está presente em diversos processos e muita coisa aconteceu e a consciência sobre temas ambientais da sociedade em geral é diferente de 20 anos atrás. De acordo com Crespo (2012), o indicador mais evidente está no número de pessoas que espontaneamente não sabiam mencionar um problema ambiental no Brasil, na sua cidade ou no seu bairro. Este número variou de $46 \%$ em 1992 para $10 \%$ em 2012. Conceitos sofisticados como "desenvolvimento sustentável", "consumo sustentável" ou "biodiversidade" já fazem parte do repertório de muitos brasileiros, e que este percentual tende a evoluir pelas mídias que vem dando mais espaço ao tema e traduzindo para o dia a dia a aplicação de tais conceitos. A autora a ponta que a noção de meio ambiente é a que mais sobressai quando os brasileiros pensam na Rio+20, e que esse "meio ambiente" é cada vez menos "naturalista" emitem mais preocupação com o lixo, o saneamento e outros problemas urbanos.

No entanto, ações e opiniões não parecem ser suficientes para criar o entendimento científico que poderia embasar uma compreensão do mundo e da vida adequados para a superação da crise ecológica. Em alguns casos a mobilização ainda é gerida pelo temor das catástrofes ou por uma adesão moral:

Nós conseguimos, nesses vinte anos, fazer com que as pessoas dialoguem sobre algumas questões, principalmente mudanças climáticas que, por mais que as pessoas não entendam o conceito, ou exatamente o que são gases de efeito estufa, elas hoje refletem. Por exemplo, quando há desmoronamento nas áreas de risco, as pessoas refletem: 'falta a mata, vegetação das encostas, e essas são áreas que estão expostas', e isso elas já vinculam à questão das mudanças climáticas (Doroty Martos). 
Em outro momento de seu depoimento, Aron Belinky problematiza este assunto, que, segundo ele,

[...] aparece nas pesquisas: as pessoas tem medo, da poluição, de cair a encosta, enchente... Esse medo pode ser um viés importante, não para ser pontecializado e aterrorizar as pessoas, não é este o ponto, mas no sentido de você dizer 'olha vamos viver bem, felizes, sem estas coisas todas' (Aron Belinky).

Outro aspecto abordado pelos entrevistados é referente a não mudança de comportamento das pessoas para diminuir a pegada ecológica individual e coletiva. Em relação à aprendizagem, a mudança de comportamento é um indicador efetivo: podemos dizer que não havendo mudança, não houve aprendizagem.

os processos de Educação Ambiental deixam muito a desejar, pois a mudança de postura avançou muito pouco no período analisado. Aumentou a consciência do brasileiro, mas não há o reflexo dessa consciência na prática, ainda não... Ainda há o desejo de consumo de carros, por exemplo, e não vejo as pessoas fazerem opções que poderiam reduzir o impacto negativo de sua forma de vida sobre patrimônio natural (Thais Corral).

Valendo-se principalmente dos depoimentos recolhidos, podemos concluir que, sem dúvida, os 13,5 milhões de pessoas e 21 mil escolas que participaram das Conferências Nacionais Infanto-juvenis pelo Meio Ambiente nos anos 2003, 2006 e 2009, os 163 painéis selecionados que foram apresentados na categoria Educação Ambiental Escolarizada do VII Fórum Brasileiro de Educação Ambiental (FBEA), e a implantação das 5.679 Comissões de Meio Ambiente e Qualidade de Vida / Com-Vida, um espaço educador sustentável que potencializa as ações de EA no ensino fundamental e no ensino médio, nos mostram uma dinâmica relacionada aos temas da sustentabilidade acontecendo nas escolas brasileiras.

\section{Conclusões}

Procuramos, até aqui, trazer ao debate a reflexão sobre como se constituiu o campo da EA no período e sobre a influência das Conferências, a partir dos autores referenciados, das análises de jornalistas, dos especialistas pesquisados e das lideranças. Entendemos que os elementos apresentados sinalizam avanços, o campo vem se aprofundando qualitativamente, de modo diverso e rico. 
Por se tratar de um processo de educação permanente, a EA está em curso, enfrenta desafios, e deve abordar questões emergentes com relação a segurança climática, acidentes ambientais, entre outros. Porem é preciso considerar a urgência de internalizar a consciência desenvolvida e transformála em mudança de fato. No entanto estamos cientes de que 20 anos ainda é pouco tempo para que as mudanças culturais e transformadoras da sociedade estejam plenamente implantadas.

Em relação aos objetivos formulados no início desse estudo, verificamos que a partir de 1992 houve a emergência e a consolidação de várias práticas sociais e de políticas públicas que favoreceram o desenvolvimento da EA no Brasil. No entanto, a análise permitiu enxergar que ainda permanecem algumas inquietações, pois os avanços que aconteceram não decorrem exclusivamente da EA, que muitas vezes é hipervalorizada em sua capacidade de promover mudanças complexas.

Outro aspecto relevante é que, embora seja generalizada a concordância quanto à existência de uma crise ambiental e social contemporânea, é notório que os entendimentos sobre as causas e soluções para esta são muitas vezes divergentes. Nos 20 anos que se passaram entre as duas Conferências da ONU, muito foi feito pela EA, por parte de alguns governantes e pela própria capacidade natural de adaptação e mudança dos sistemas culturais e econômicos da sociedade, buscando sua sustentação e reprodução.

Cremos, por fim, que a Educação Ambiental vem influenciando o pensamento e a vida dos brasileiros, e deve seguir adiante a tarefa mais difícil dos educadores ambientais: sua própria superação enquanto agente transformador da sociedade.

\section{Referências}

BOSI, E. O tempo vivo da memória: ensaios de psicologia social. São Paulo: Ateliê Editorial, 2003.

BOVO, M.C. Interdisciplinaridade e transversalidade como dimensões da ação pedagógica. Revista Urutágua, Revista Acadêmica Multidisciplinar. Quadrimestral, n. 07, ago., set., out., nov., Maringá (PR), 2007.

BRASIL. Ministério do Meio Ambiente dos Recursos Hídricos e da Amazônia Legal. Programa Nacional de Educação Ambiental. Brasília, 1997.

BRASIL. Lei no 9.795, de 27 de abril de 1999. Dispõe sobre a educação ambiental, institui a Política Nacional de Educação Ambiental e dá outras providências. Diário Oficial [da] República Federativa do Brasil, Brasília, 28 abr. 1999.

BRASIL. Parâmetros em Ação: análise e perspectivas. Brasília: MEC/SEF, $2002 a$. 
CMMAD. Comissão Mundial Sobre Meio Ambiente e Desenvolvimento. Nosso futuro comum. Rio de Janeiro: Editora FGV, 1988.

CRESPO, S. O que o brasileiro pensa do meio ambiente e do consumo sustentável: mulheres e tendências de consumo atuais e futuras no Brasil Relatório analítico das entrevistas em profundidade. Rio de Janeiro: Publit, 2012.

DUAILIB, M. Prefácio. In: JUNQUEIRA, V.; NEIMAN, Z. (Org.). Educação Ambiental e conservação da biodiversidade: reflexões e experiências brasileiras. Barueri SP: Manole, 2007.

FONTANELA, L.B. Educação Ambiental como Processo Transversal do Currículo Escolar. Dissertação de Mestrado em Engenharia de Produção da Universidade Federal de Santa Catarina, Florianópolis, 2001.

GIRARDI, G. Mais ambição poderia não resultar em mais ações. O Estado de S. Paulo, edição de 24/06/2012.

GUIMARÃES, M. A dimensão ambiental na educação. Campinas (SP): Papirus, 1995.

GUIMARÃES, R.P. Agenda 21 e desenvolvimento sustentável. Revista Debates Sócio Ambientais, v. 4, n. 11, nov./fev. 1998/ 1999.

LAYRARGUES, P.P. Do ecodesenvolvimento ao desenvolvimento sustentável: evolução de um conceito?. Revista Proposta, Rio de Janeiro, v. 24, n. 71, p. 15, 1997.

LEFF, E. Saber Ambiental: sustentabilidade, racionalidade, complexidade, poder. Petrópolis (RJ): Vozes, 2001.

LEITÃO, M. O intangível na Rio+2”. O Globo, edição de 23/06/2012.

MARCONDES, D. O futuro que queremos?. Envolverde. 03 de julho de 2012. Economia. Disponível em http://envolverde.com.br/economia/artigoeconomia/o-futuro-que-queremos/. Acessado 10/04/2012.

MENDONÇA, P.R. Avaliação dos parâmetros em ação - meio ambiente na escola: um programa de Educação Ambiental do Ministério da Educação. Anais do II Encontro Associação Nacional de Pós Graduação e Pesquisa em Ambiente e Sociedade - ANPPAS. Indaiatuba (SP), 2004.

MININNI-MEDINA, N. Educação Ambiental: curso básico à distância: Educação e a Educação Ambiental I. 2 ed. 5 v. Brasília: MMA, 2001.

NAKED G.M.; LUCCA, S.R. Desenvolvimento e aplicação de modelo integrado de certificação do sistema de gestão ambiental para empresas com mais de um site. Revista Techoje: Instituto de Educação Tecnológica, s/d. 
NIEVES ALVAREZ, M. Valores e temas transversais no currículo. Trad. Daisy Vaz de Moraes. Porto Alegre: Artmed, 2002, 184pp.

NOVAES, W. Ponto de chegada ou de partida?. O Estado de S. Paulo, edição de 24/06/2012.

PORTO-GONÇALVES, C.W. O desafio ambiental. Rio de Janeiro: Record, 2004.

RAMALHO, M.U. A Educação Ambiental e o Desenvolvimento da Cidadania no Ensino Fundamental. Araraquara (SP): Legis Summa, 2004. p.204

RATTNER, H. Sustentabilidade: uma visão humanista. Ambiente \& Sociedade, n.5, $2^{\circ}$ Semestre de 1999. Campinas, Unicamp, 1999, p. 233-240.

RODRIGUES, A.B. (Org.) Turismo rural: práticas e perspectivas. São Paulo: Contexto, 2001.

ROSA, A. C. M. As grandes linhas e orientações Metodológicas da Educação Ambiental. Unidade I, In: MININNI-MEDINA, N.; LEITE, A.L.T.A (Orgs). Educação Ambiental: curso básico à distância: educação e educação ambiental I. Brasília: MMA, 2001, 5v., 2ªed.

SACHS, I. Ecodesarrollo: Desarrollo sin Destrucción, México: El Colegio de Mexico, 1982.

SACHS, I. Caminhos para o desenvolvimento sustentável: ideias sustentáveis. Rio de Janeiro: Garamond, 2002.

SACHS, I. Desenvolvimento: includente, sustentável, sustentado. Rio de Janeiro: Garamond. 2004.

SATO, M.; CARVALHO, I.C. (Org.). Educação Ambiental: pesquisa e desafios. Porto Alegre: Artmed, 2005. 232p.

SATTERTHWAITE, D. Como as cidades podem contribuir para 0 Desenvolvimento Sustentável. In: MENEGAT, R.; ALMEIDA, G. (org.). Desenvolvimento Sustentável e Gestão Ambiental nas Cidades: estratégias a partir de Porto Alegre. Porto Alegre: UFRGS Editora, pp. 129-167, 2004.

SORRENTINO, M.; TRAJBER, R.; MENDONÇA, P.; FERRARO-JUNIOR, L.A. Educação ambiental como política pública. Educação e Pesquisa, São Paulo, v. 31, n. 2, p. 285-299, maio/ago. 2005.

TOZZONI-REIS, M.F.C. Environmental education: theoretical references in higher education. Interface Comunic, Saúde, Educ, v.5, n.9, p.33-50, 2001.

TRAVASSOS, E. G. A Prática da Educação Ambiental nas Escolas. Porto Alegre: Mediação 2004.

VEIGA, J. E. Cidades Imaginárias: o Brasil é menos urbano do que se calcula. Campinas: Editora da Unicamp, 2005.

VIANA, V. Os 20 anos da Rio92 devem ser comemorados. O Estado de S. Paulo, edição de 24/06/2012. 